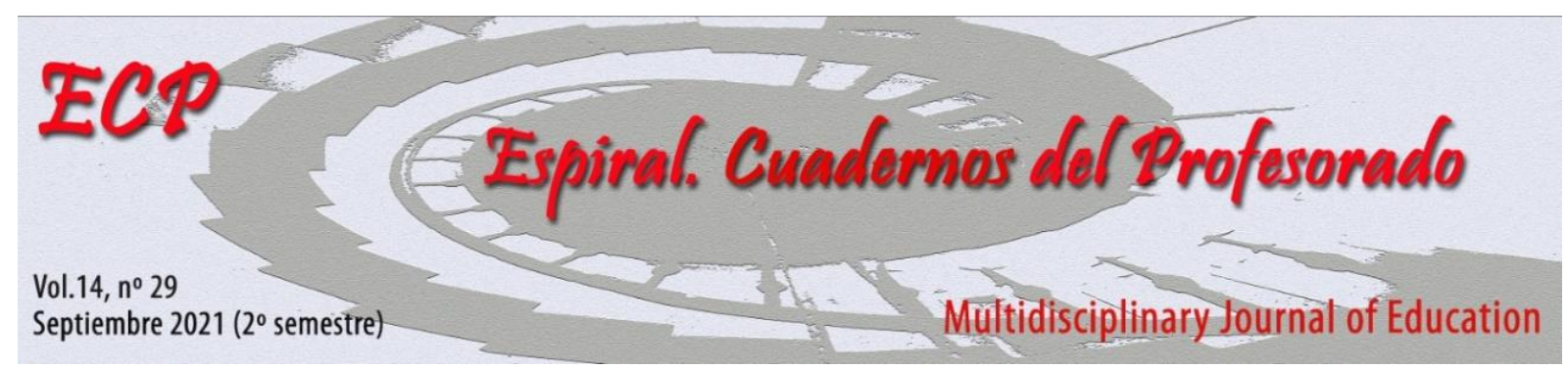

\title{
Creación lingüística y literaria: nuevos soportes digitales en el ámbito educativo
}

\section{Linguistic and literary creation: new digital support in the educational field}

\author{
María del Carmen Quiles Cabrera \\ Universidad de Almería, España \\ Correspondencia: María del Carmen Quiles Cabrera, Universidad de Almería \\ Presentación \\ Email: qcabrera@ual.es
}

Los avances de la tecnología en las comunicaciones, que en un principio irrumpieron como algo novedoso, se han instalado de tal manera en nuestra cotidianeidad que resulta ya muy difícil desligarnos de la influencia que el mundo digital ejerce en todos los ámbitos de la vida. A día de hoy a ninguno nos es ajeno atender a los saludos que nos llegan a través de un grupo de WhatsApp, leer la prensa mediante el ordenador o revisar el correo electrónico usando el teléfono móvil. No cabe duda de que las formas de y para la comunicación se han transformado generando nuevos modos y espacios (Martínez Ezquerro, 2015). Recientemente reflexionábamos sobre esta cuestión en un trabajo elaborado en torno a los booktubers y bookstagrammers (Quiles Cabrera, 2021) y su papel en la difusión de las producciones literarias y los nuevos géneros discursivos. Este fenómeno adquiere un interés e importancia fundamental para la socialización y para el desarrollo de competencias esenciales en el plano educativo como la lectura literaria, según se ha venido poniendo de manifiesto en otras reflexiones (Paladines Paredes y Margallo González, 2020; Paterna Roda, 2018). Al formar lectores y lectoras competentes, hemos de recoger el eco de los cambios y transformaciones sociales para lograr una confluencia entre los entornos clásicos y los nuevos ecosistemas de producción-recepción textual a los que están habituados los aprendices (Martos Núñez y Campos Fernández-Fígares, 2013). Cada vez son más los adolescentes que se acercan a los libros por recomendación de algún influencer que, desde sus redes sociales, capta la atención de miles de seguidores; se trata de un hecho que no podemos pasar por alto, porque esa primera aproximación puede ir evolucionando hacia un contacto mucho más estrecho con obras universales e incluidas en el canon. Pensemos también en la vinculación que todo esto tiene con el cine o las series de televisión. Se trata de un proceso en el que ambos ámbitos se retroalimentan: la adaptación cinematográfica alcanza un gran éxito, un youtuber menciona la referencia literaria e inmediatamente se genera un fenómeno fan en torno a la obra, los personajes e incluso el autor. Si a todo esto le sumamos la apertura de parques temáticos, rutas o actividades paralelas en favor de un turismo cultural cada vez en mayor auge, no podemos negar la trascendencia que todo esto adquiere a la hora de conformar lectores desde un contexto que, en un principio, nada tiene que ver con la escuela, pero que sí ha de ser tomado en cuenta por su inmenso potencial al servicio de una enseñanza de la literatura eficaz y con garantías. El desarrollo de competencias diversas queda garantizado cuando incluimos en nuestras aulas esos textos urbanos que son ya formas de expresión cotidianas, donde los usuarios se manifiestan y proyectan su concepción del mundo. Pensemos en el juego tan grande que nos ofrecen las memes, por ejemplo (Camas, Valero y Vendrell, 2018). Por este motivo, se ha hablado de la 
necesidad de repensar la didáctica de la lengua y la literatura (Campos Fernández-Fígares y Quiles Cabrera, 2020), porque nos encontramos en un escenario muy diferente al que asistíamos en los años ochenta, cuando el área de conocimiento se conformaba como disciplina autónoma.

Las nuevas plataformas, aplicaciones y dispositivos han puesto sobre el tablero un juego, cuyas reglas conocen muy bien las nuevas generaciones. Los espacios digitales y las redes sociales, tan frecuentadas por nuestros niños y adolescentes, llevan desde hace tiempo propiciando la aparición de nuevas formas de escritura y de lectura y, por ende, de creación, difusión y recepción del texto literario. Los propios conceptos previamente mencionados - booktuber y booktagrammer, a los que se suman otros como booktoker-, todos ellos epitextos que giran en torno a la lectura y la recomendación de una obra. Pero también estos espacios se prestan a la creación; muchos autores jóvenes comienzan a aficionarse a la escritura literaria a través de estos entornos virtuales, de ahí por ejemplo el fenómeno tan interesante de la fanfiction (Martos García, 2009) o el importante papel que la ciberpoesía (Campos Fernández-Fígares y Escandell, 2019) juega en este sentido. De lectura obligada resulta el libro coordinado por Remedios Sánchez sobre la joven poesía española en la era de internet (2018), así como la reflexión que esta misma autora introduce sobre la poesía vista por los millenials en su volumen dedicado a la poesía española contemporánea (2018).

Además, la virtualidad se ha implantado como práctica habitual no solo fuera, sino dentro de las aulas, especialmente ante la situación pandémica a la que asistimos. El contexto educativo ha visto aumentar sus vías de comunicación, de intercambio e interacción entre los usuarios, esto es, entre la comunidad docente y discente (Santa Medina, 2021; Sotelo y González, 2021).

La necesidad de una alfabetización digital y mediática por parte de todo el colectivo, de la que se ha venido hablando desde hace mucho tiempo (Altamirano, 2021; Cordón, 2016; Kendall y McDougall, 2012), se ha hecho patente de la manera más clara en el último año. De ahí la necesidad de reflexionar sobre este nuevo escenario al que asistimos en el que la educación lingüística y literaria juega con unas reglas diversas, plurales y sujetas a la evolución del mundo digital.

\section{Nuestro Monográfico}

Así, con el presente monográfico hemos reunido siete trabajos fundamentales que abordan toda esta temática desde diferentes perspectivas. Todos ellos, en su conjunto, nos ayudarán a entender el panorama actual en torno a la creación literaria y la formación de nuevos lectores. Comenzamos con el análisis de una plataforma específica para escribir y comentar literatura en la red, una práctica que cada vez más se reconoce entre las generaciones más jóvenes. Moisés Selfa Sastre y Enric Falguera son los encargados de situarnos ante el espacio digital clubdeescritura.com. Continuamos el monográfico con el trabajo de Manuel Romero Oliva, Blanca Florido y Hugo Heredia, de la Universidad de Cádiz, quienes nos aproximan al epitexto editorial en los libros de no ficción, entre los que destacan los nacidos con la virtualidad y las tecnologías de la información y la comunicación. El tercer artículo nos va introduciendo en el contexto de las aulas de una forma más directa y avanzamos desde la Educación Secundaria, con el trabajo de Pablo Aparicio (Universidad de Granada) centrado en un análisis semiótico a través de los clásicos desde la tradición a la realidad 2.0, al ámbito universitario tanto dentro como fuera de España. De ahí que a la reflexión de Daniel Fuentes González (Universidad de Almería), que gira en torno a las teleclases -cuyo uso, como decíamos, se ha incrementado de manera exponencial en los dos últimos años con motivo de la pandemia-, se sumen los de Fernando Valverde y Nieves García Prados (Universidad de Virginia, EEUU), junto al de Natasha Leal Rivas (Universidad Federico II, Italia). Los dos autores primeros se adentran en las problemáticas reales que presenta la virtualidad en la enseñanza de una lengua extranjera en la Educación Superior, y la segunda autora nos muestra cómo incide el aprendizaje en línea en la adquisición pragmática de las lenguas. El monográfico se cierra con una visión que nos llega también desde un contexto extranjero como es el de Portugal. Ángela Balça y Paulo Costa nos presentan el cierre perfecto; con su trabajo, insisten en la importante repercusión del mundo digital en la creación literaria y nos sitúan ante la realidad de un país vecino, lo cual nos sirve de referencia a la hora de dibujar nuestro presente y construir nuestro futuro en relación con los entornos que nos rodean. 


\section{Referencias}

Altamirano, S. G. (2021). Perfil de alfabetización mediática de estudiantes y docentes de educación superior. Revista CPU-e, 32, 88-110.

Camas, L. A., Valero, A., \& Vendrell, M. (2018). "Hackeando memes": cultura democrática, redes sociales y educación. Espiral. Cuadernos del profesorado, 11, 23, 120-129. https://doi.org/10.25115/ecp.v12i23.2017

Campos Fernández-Fígares, M., \& Escandell, D. (Coord.) (2019). Poesía en red y ciberpoesía. Fundación Cultural Miguel Hernández. https://dialnet.unirioja.es/servlet/libro?codigo=739240

Cordón, J.A. (2016). La lectura digital y la formación del lector digital en España: la actividad de la

Fundación Germán Sánchez Ruipérez y el Proyecto Territorio Ebook. Álabe, 13. http://dx.doi.org/10.15645/Alabe2016.13.11

Kendall, A. \& McDougall, J. (2012). Alfabetización mediática crítica en la postmodernidad. Comunicar: Revista Científica Iberoamericana de Comunicación y Educación, 38, 21-29. https://doi.org/10.3916/C38-201102-02

Martínez Ezquerro, A. (2015). Lengua, literatura y nuevos enfoques tecnológicos. En N. Ibarra, J. Ballester, M. Carrió y F. Romero (Coords.), Retos en la adquisición de las literaturas y de las lenguas en la era digital. Universidad Politécnica de Valencia.

Martos García, A. (2009). Sagas y fan fiction, escritura literaria y cultura juvenil. Lenguaje y Textos, 9, 167-175.

Martos Núñez, E. \& Campos Fernández-Fígares, M. (2013). Diccionario de nuevas formas de lectura y escritura. Santillana.

Paladines Paredes, L. \& Margallo González, A. Mª (2020). Los canales booktuber como espacio de socialización de prácticas lectoras juveniles. Ocnos: revista de estudios sobre lectura. 19, 1, 55-67.

Paterna Roda, A. (2018). La comunidad Booktube como propuesta para trabajar la animación a la lectura. En E. López Meneses et al. (Coords.), Experiencias pedagógicas e innovación educativa: aportaciones desde la praxis docente e investigadora (pp. 987-998). Octaedro.

Quiles Cabrera, Ma . C. (2021). Textos poéticos y jóvenes lectores en la era de internet: de "booktubers", "bookstagrammers" y "followers". Contextos educativos: Revista de educación. 25, 9-22. https://doi.org/10.18172/con.4260

Sánchez García, R. (2018). Así que pasen treinta años... Historia interna de la poesía española contemporánea (1950-2017). Akal.

Sánchez García, R. (Coord.) (2018). Nuevas poéticas y redes sociales. Joven poesía española en la era digital. Siglo XXI.

Santa Medina, R. (2021). El e-Learning en Educación Primaria como consecuencia de la situación generada por el Covid-19: un estudio de caso. Revista Interuniversitaria de Investigación en Tecnología Educativa. 10, 121-130. https://doi.org/10.6018/riite.439831

Sotelo, J. \& González, J. (Coords.) (2021). Digital media: el papel de las redes sociales en el ecosistema educomunicativo en tiempos de Covid-19. McGraw-Hill Interamericana de España. 